\title{
An Empirical Analysis of the Effects of Agricultural FDI on the International Competitiveness of Agricultural Products in China
}

\author{
Yanqing Jiang*, Gaoyan Shi \\ School of Economics and Finance, Shanghai International Studies University, Shanghai, China \\ Email: ${ }^{*}$ yjiang@shisu.edu.cn
}

Received 21 July 2014; revised 20 August 2014; accepted 18 September 2014

Copyright (C) 2014 by authors and Scientific Research Publishing Inc.

This work is licensed under the Creative Commons Attribution International License (CC BY). http://creativecommons.org/licenses/by/4.0/

(c) (i) Open Access

\begin{abstract}
Under the background of the reform and opening-up, as well as continuous economic growth and development, China's attractiveness for foreign direct investment (FDI hereinafter) has shown an increasing trend year after year. However, FDI is distributed unevenly in the three broad industrial sectors. Through our investigation to the utilization of agricultural FDI, we find that the size and scale of FDI utilized in agriculture lagged far behind with manufacturing and service sectors and distributed unevenly across geographical regions. The "agriculture, rural areas and farmers" issue has always been one of the most important and difficult issues in the process of China's economic reform. The main focus of this paper is on what impacts FDI has on the agricultural sector of the macroeconomy and how we should fully utilize FDI in order to alleviate trade deficit in agricultural products and enhance the international competitiveness of agricultural goods in China.
\end{abstract}

\section{Keywords}

International Competitiveness, Agricultural FDI, Scale Operation, Granger Causality Test

\section{Introduction}

China has been a huge agricultural country since ancient times. As the very foundation of domestic economy, the importance of agriculture cannot be overemphasized. Given both the low development level of industrialization and marketization in the agricultural sector and the low labor quality of rural population, as well as restric-

${ }^{*}$ Corresponding author. 
tions associated with agricultural productions and sales conditions, FDI in agriculture accounts only for a small proportion of the whole gross FDI in China [1] [2].

Compared to other industries, agriculture is relatively special and prone to being affected by natural and market conditions. Due to such unfavorable factors as the low comparative benefits of agricultural productions, slow advancement of agricultural technology, as well as a long production cycle, agriculture is the main industry under every state's key protection [3]. In China, with the small scales, low organizational degrees, and low processing levels in agricultural products, as well as long production cycles, agricultural productions are often unable to make prompt market adjustments when confronted with rapidly changing market situations [4]. The slow adjustment processes pose a great influence on the competitiveness of agriculture and agricultural goods. In recent years, the Chinese government has continuously put more and more emphasis on the basic importance of agriculture, by encouraging all sorts of social capital to be invested in agriculture, including foreign investments [5]. So, we are interested in what potential roles FDI can possibly play in the development of China's agricultural sector, and how we can accelerate China's agricultural takeoff by properly utilizing FDI. This paper thus focuses on an empirical investigation of what potential impacts FDI may exert on the agricultural sector of China's macroeconomy and how we should fully utilize FDI in order to alleviate trade deficits in agricultural products and enhance the international competitiveness of agricultural goods in China.

\section{International Competitiveness of Agricultural Products}

International competitiveness in terms of the agricultural products is associated with international competitiveness of the agricultural sector. Genqun Li (2012) summarizes various understandings of the concepts of international competitiveness put forward by different research organizations and scholars in recent years, and provides a broad concept of international competitiveness in terms of agricultural products after a careful analysis of the trade configuration of agricultural products. To gain a stronger international competitiveness, agricultural products must meet conditions such as whether the products can meet the demands in the international market, get sustained profitability, maintain a stable international market share, and so forth. Namely, the international competitiveness of agriculture in a country or region means it can produce agricultural products which meet the needs of the international market demand under the condition of fair and free conditions, and keep its market share for quite a long period of time, and as well as have the ability to remain consistently profitable [1]. There are also scholars who measure the international industrial competitiveness of agriculture from four dimensions including price competitiveness, quality competitiveness, reputation competitiveness and marketing competitiveness [2] [6] [7].

In order to measure the international competitiveness of agricultural products, we can apply some evaluation indexes to conclude the overall level of China's international competitiveness in agricultural products, and then prescribe the possible directions for agricultural development in China. Competitiveness indicators vary substantially whereas this paper indicates that an industry's competitive strength can be reflected by its share in the international market, as well as by the imports and exports of its products, to some extent. Expansion of the market share in the international market reflects the improvement of the international competitiveness of the product involved to a certain extent, and an increase of the proportion of net exports to total exports is also a signal of more competitive products. Below we depict the trend of imports and exports of agricultural products in China for the period 2000-2012. Data is obtained from the United Nations food and agriculture organization (FAO database) database.

Figure 1 shows the trend of consistently growth and slight fluctuations of agricultural products' exports and imports. Since 2002, with the rapid development of China's foreign trade of agricultural products though, imports of agricultural products outperform exports continuously and it appears to be clear that China became a net importer of agricultural products from a net exporter. Apart from the fact that trade deficit decreased in 2005, agricultural trade deficit did not turn to surplus in more recent years, and this trend was getting even worse. Growing trade deficits indicate China's agricultural products have disadvantageous competitiveness in the international market.

Genqun $\mathrm{Li}$ (2012) adopts indicators such as the international market share, the trade competition index and the revealed competition to evaluate China's agricultural competitiveness and compares various indicators of agricultural products' competitiveness with those of the United States, Brazil, India and other countries. It is concluded that the overall international competitiveness of China's agricultural products were getting weaker 


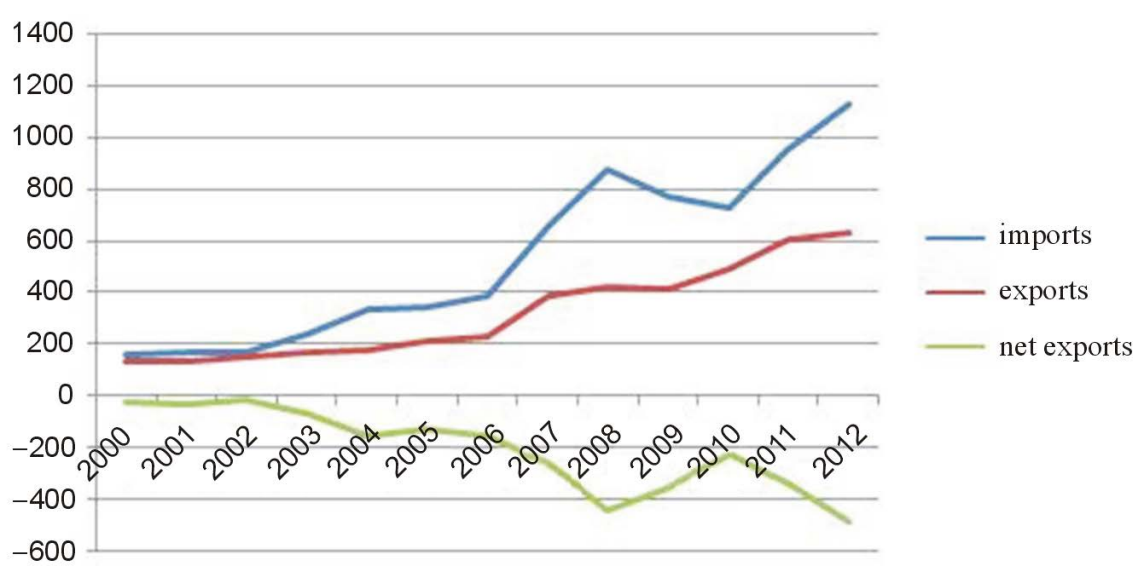

Figure 1. Agricultural trade amount for the period 2000-2012 (Unit: 100 million dollars).

year by year. While land intensive agricultural products lose their competitive advantages, some labor-intensive agricultural products also gradually lose the comparative competitiveness advantage [1].

\section{Empirical Analysis}

In the current paper, after careful consideration and selection, we choose the international market share and trade competitive index constitute the needed index system for our following empirical analysis, which aims to manifest the international competitiveness of Chinese agricultural products in a relatively accurate way.

\subsection{International Market Share}

The International Market Share is defined as the ratio of the quantity of exports of one product in a country or district to the total exports of similar kind of products over the world, which is often used to indicate the international competitiveness. Formally, we can write

$$
M_{i}=\frac{X_{i}}{X_{w}}
$$

which can be conveniently converted into a percentage value. Here $M_{i}$ stands for the international market share of product $i$ in a country or district, $X i$ stands for the exports of product $i$ in a country or district, and $X_{w}$ stands for the total exports of product $i$ in the world.

It is generally believed that if the international market share of a product in a country or region is higher, the international competitiveness is stronger, and weaker conversely. If $M_{i}>20 \%$, it generally shows that the product bears a fairly strong international competitiveness. If $10 \%<M_{i}<20 \%$, the product has a moderate international competitiveness. If $5 \%<M_{i}<10 \%$, the product's international competitiveness is generally weak, and if $M_{i}<5 \%$, then the product's international competitiveness is even weaker.

According to data from China's National Bureau of Statistics, after calculating the exports of agricultural products on the international statistical yearbooks' data from 1995 to 2012, (the original data source is the world trade organization database, and China's exports of agricultural products are based on mainland China. Data is limited by year) we obtain the international market share of agricultural products from 1992-2010. It can be seen from Figure 2 that in recent years, the international market share of agricultural products over time is well below $5 \%$, showing that the competitiveness is not high.

\subsection{Trade Competitive Index}

The Trade competitive index refers to the proportion of net exports of one product to its total trade value in one country. To calculate it, we have

$$
T C_{i}=\frac{X_{i}-M_{i}}{X_{i}+M_{i}}
$$




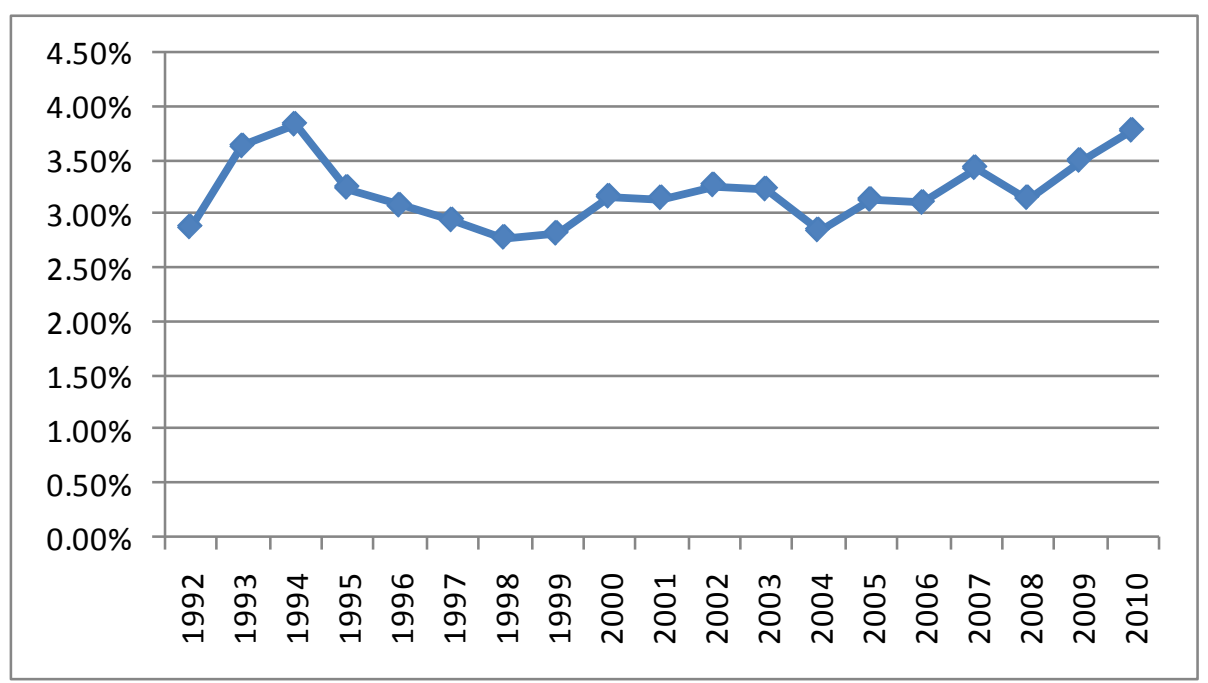

Figure 2. The trend of the international market share of agricultural products.

which is also often expressed in a percentage value. $T C_{i}$ stands for the trade competitive index, $X_{i}$ stands for exports of product $I$, and $M_{i}$ stands for the country's total imports of product $i$. The competitive index values' range is $(-1,1)$ : when its value equals zero, it shows that imports and exports of product $i$ are balanced in the country while when the value is greater than zero, exports of product $i$ exceed its imports in the country, which indicates that this product has a certain extent of competitiveness in the international market. The closer the value to unity, the stronger the international competitiveness is. On the contrary, if it is less than zero, the imports of product $i$ exceed exports in the country, indicating that this product has a weak competitiveness in the international market. In addition, the closer the index is to -1 , the weaker the international competitiveness.

According to data from China's National Bureau of Statistics, after calculating the exports of agricultural products on the international statistical yearbooks' data from 2000 to 2012 using the formula above, we obtain the trade competitive index (The original data source is the world trade organization database. Data is limited by year).

It can be seen from Figure 3 that the competition index of China's agricultural products trade is quite volatile, hitting a low in 2008 (reaching -0.35), which coincides with the strikes of the international financial crisis. At the beginning of the 21 st century it is quite close to 0 , showing a more or less balance of foreign trade. However, afterwards, the balance of trade has been in a negative state, indicating the overall competitiveness of China's agricultural products in the international market is relatively weak.

\section{The Granger Causality Test}

The Granger causality test is widely used to analyze the causal relationship between economic variables. In case of time series data, the granger causality relation between two economic variables $X$ and $Y$ is defined as: when including past information about variables $X$ and $Y$, the forecasting effect for variable $Y$ is better than that only including past information of $Y$, namely variables $X$ helps to explain the change of $Y$ in the future, then variable $X$ is considered to be the granger reason of variable $Y$. The prerequisite for granger causality test is that the time series data must exhibit stability. Otherwise there may be a false regression problem. Thus before the granger causality test, we should have a unit root test to ensure time series stationarity of each index. ADF test is commonly used to test each index sequence about its stationarity.

Specifically, first of all we need to do unit root test on two variables that we are interested in, the international market share, and the agriculture FDI data. As shown in Table 1, since in the ADF test of international market share including intercept and trend, p value is 0.635 , far more than the general significance level of $5 \%$, so we can't reject the null hypothesis that this variable contains unit root, meaning that it is not stable; Likewise, ADF test of the agriculture FDI also shows it is not stable. However, the first order differential score of these two variables are relatively stable. The following charts show ADF test results of first order difference of agriculture FDI without intercept and trend. 


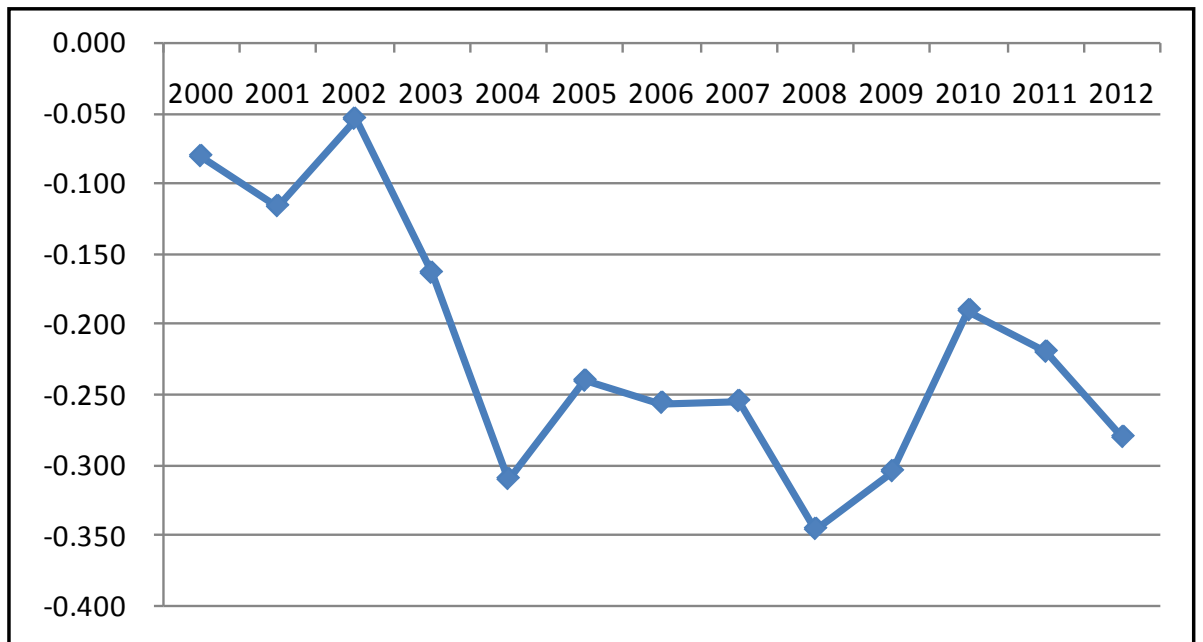

Figure 3. Trend of trade competitive index.

Table 1. The unit root test.

\begin{tabular}{|c|c|c|c|}
\hline \multicolumn{4}{|c|}{ Null Hypothesis: D (DFDI) Has a Unit Root } \\
\hline \multicolumn{4}{|l|}{ Exogenous: None } \\
\hline \multicolumn{4}{|c|}{ Lag Length: 0 (Automatic Based on SIC, MAXLAG = 1) } \\
\hline \multirow{2}{*}{\multicolumn{2}{|c|}{ Augmented Dickey-Fuller Test Statistic }} & t-Statistic & Prob. \\
\hline & & -3.624042 & 0.0025 \\
\hline \multirow[t]{3}{*}{ Test Critical Values: } & 1\% Level & -2.847250 & \\
\hline & 5\% Level & -1.988198 & \\
\hline & 10\% Level & -1.600140 & \\
\hline
\end{tabular}

After the Granger Causality Test about agriculture FDI and international market share through E-views, the result is shown in Table 2. The Granger causality test results show that the p value of $F$ statistics is very large, far higher than the average 5\% significance level, so we cannot reject the null hypothesis, namely mutual causality does not exist between the agricultural product international market share and agriculture FDI.

\section{Discussion}

From the perspective of theoretical analysis, it seems that agriculture FDI growth is able to bring unambiguously positive influences to the international competitiveness of agricultural products. However, empirical analysis shows that agricultural FDI inflows in the recent ten years have not succeeded in promoting the international competitiveness of China's agricultural products in any discernable pattern. Namely, there is no causality being detected. On the one hand, this is closely related to the actual utilization and distribution of agriculture FDI. Yet on the other hand, a more important reason is that the competitiveness is profoundly shaped by system factors like slow process of agricultural modernization and industrialization in China. The stimulating effect of the FDI has not been as great as expected. Perhaps its effect has been offset by the negative impact of agricultural exports. However, from our point of view, the process of introducing FDI to agriculture cannot be stopped even so. What should be paid more attention to is how to better introduce high-quality foreign capital and how to utilize foreign capital to promote the industrialization of agriculture to increase farmers' income, which are left to the consideration of policy makers. In this paper, based on our findings, we can tentatively make the following suggestions.

First, the integration of land resources and encouragement of moderate scale management aiming at promoting the industrialization of agriculture should be strengthened. Due to low per capita land, peasant household production is in small scale, mostly scattered, and with low organizational degree in China, which seriously hindered the improvement of agricultural labor productivity. Given the Chinese rural conditions and the actual 
Table 2. The granger causality test.

\begin{tabular}{llll}
\hline Pair-Wise Granger Causality Tests & & \\
Date: 09/14/13 Time: 00: 33 & & & \\
Sample: 20002011 & & & \\
Lags: 2 & Obs & F-Statistic & Probability \\
Null Hypothesis: & 8 & 0.99732 & 0.46551 \\
DINDEX Does Not Granger Cause DM & & 0.32448 & 0.74547 \\
DM Does Not Granger Cause DINDEX & & & \\
\hline
\end{tabular}

utilization of arable land, to promote moderate scale operation is a good way to improve the efficiency of land use. Without depriving farmers of their land contract rights, and only by collecting the decentralized land of the peasant household together, we can produce in large-scale, pushing the industrialization of agricultural production. Agricultural industrialization through all kinds of organizations will connect mass farmers, and combine the production and processing of agricultural products sales, overcoming the contradiction between small-scale production and big market, extending the industrial chain of traditional agriculture, which is a effective way to improve agricultural productivity and agricultural product international competitiveness [3]. In addition, we can nurture some leading enterprises who have strong scientific research ability, good profitability and high degree of scale, thus to promote the development of agriculture, changing the previous peasant household management production mode to mode driven by enterprise scale. In this way agricultural products can be introduced to the international market in the form of enterprise product to participate in international competition, thereby enhancing the competitiveness of agricultural products.

Second, the adjustments associated with agriculture FDI and its regional pattern should be sufficiently made. Most investors focus on eastern regions of China, investing much less in the central and western regions, which shows an obvious accumulation effect. There are less foreign investments in the Midwest because of poor natural conditions and behindhand economy as well as low consumption level. Foreign direct investment is concentrated in the eastern region, causing labor shortages in the eastern part and then labor costs will rise, leading to the investment situation of shrinking profits in the east. If Midwest government departments take favorable measures as tax reduction or exemption, spare no effort to introduce investment companies to the Midwest, take the low-cost advantage to make full use of local labor force, then considerable benefits can be brought for the manufacturer. Balance of investment promotion and capital introduction in the central and western regions, can reduce the agricultural development gap between eastern, central and western areas, improving the overall level of China's agriculture, also the quality of China's agricultural products export, thus agricultural exports [3].

Third, we should press ahead with the reform of circulation of agricultural products, introduce foreign capital in each step of production. As FDI is restricted by the foreign economic situation, especially the financial crisis, so innovation of internal production and operation system also cannot be ignored. We should actively promote the reform of circulation of agricultural products. Due to long-term influence from the control of economic system, the circulation of agricultural products has been restricted, which creates lots of difficulties for large-scale investments and agricultural integration management. As long as this situation remains, the current utilization of foreign investment in agriculture is difficult to change, thus production, circulation and sales of agricultural products are still fraught with difficulties. That's why our country should accelerate the reform of agricultural product circulation system. In a stable agricultural products market, we should not only introduce foreign investments into agricultural production and processing field, but also the distribution and sales of agricultural products.

Fourth, wholly policy supports from the local government are urgently called for. First, various departments in local governments should adopt preferential policies and laws and regulations to attract foreign investment, especially large foreign multinational companies, and plenty of private capital to invest in China's agricultural infrastructure. Diversification of investment subjects guarantees sufficient capital of China's rural fixed asset investment, ensuring international competitiveness of agricultural products. Secondly, the government and university and other research institutions should set up complete professional and welfare mechanism, to actively attract a new generation of agricultural scientific and technological personnel to be engaged in agricultural economy. Finally, China's agriculture should take advantage of foreign direct investment opportunities, fully 
absorb and employ foreign advanced technologies, management skills and sales concepts in organizations such as family farms and similar businesses to improve qualities of agricultural products in China, thus enhance the competitive advantage of agricultural products.

\section{Concluding Remarks}

In this analysis we have focused on what impacts FDI has on the agricultural sector of the macroeconomy and how we should fully utilize FDI so as to alleviate trade deficit in agricultural products and enhance the international competitiveness of agricultural goods in China. After careful consideration and selection, we choose the international market share and trade competitive index that constitute the needed index system for our following empirical analysis, which aims to manifest the international competitiveness of Chinese agricultural products in a relatively accurate way. Our analysis has shown that agricultural FDI inflows in the recent ten years have not succeeded in promoting the international competitiveness of China's agricultural products in any discernable pattern. Namely, there is no causality being detected. For one thing, this is closely related to the actual utilization and distribution of agriculture FDI. Additionally, a more important reason is that the competitiveness is profoundly shaped by system factors like slow process of agricultural modernization and industrialization in China. The stimulating effect of the FDI has not been as great as expected. What should now be paid more attention to is how to better introduce high-quality foreign capital and how to utilize foreign capital to promote the industrialization of agriculture to increase farmers' income.

\section{References}

[1] Li, G.Q. (2012) Analysis and Study on China’s Agricultural Product International Competitiveness. Shandong University of Finance and Economics, Jinan.

[2] Liu, S.H. (2009) Research on International Competitiveness of Chinese Agricultural Product Based on Agricultural Industrialization. Wuhan University of Technology, Wuhan.

[3] Gao, Q. (2011) Empirical Analysis of the Impact of China’s Agriculture FDI on Agricultural Exports. Liaoning University, Shenyang.

[4] Jin, F.C. (2012) The Influence of Agricultural FDI Inflows to Chinese Agricultural Development. Zhejiang Industry and Commerce University, Hangzhou.

[5] Xu, Y.B. (2012) The Influence of Agricultural Use of Foreign Direct Investment on Chinese Agriculture. Chinese Academy of Agricultural Sciences, location.

[6] Wen, K.R. (2004) Analysis of the Influence Factors of Agricultural Product International Competitiveness. Huazhong Agricultural University, Wuhan.

[7] Chen, Y.M. (2005) Theory and Empirical Research on China’s Agricultural Product International Competitiveness. Guangxi University, Nanning. 
Scientific Research Publishing (SCIRP) is one of the largest Open Access journal publishers. It is currently publishing more than 200 open access, online, peer-reviewed journals covering a wide range of academic disciplines. SCIRP serves the worldwide academic communities and contributes to the progress and application of science with its publication.

Other selected journals from SCIRP are listed as below. Submit your manuscript to us via either submit@scirp.org or Online Submission Portal.
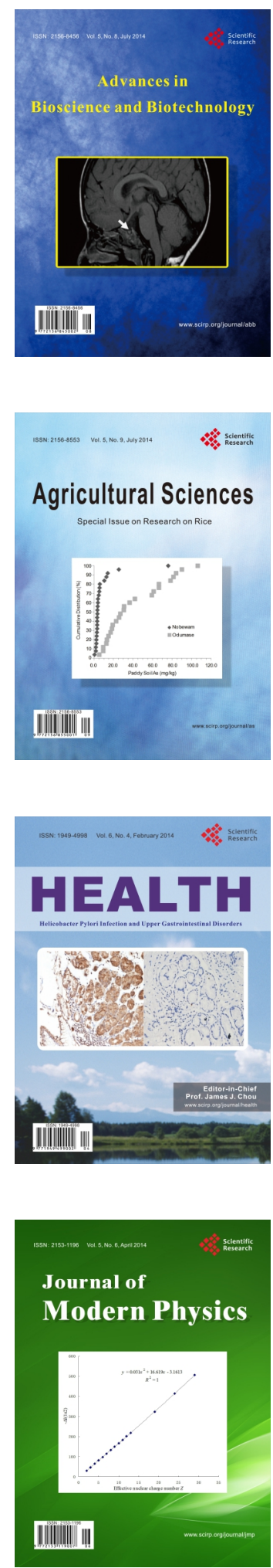
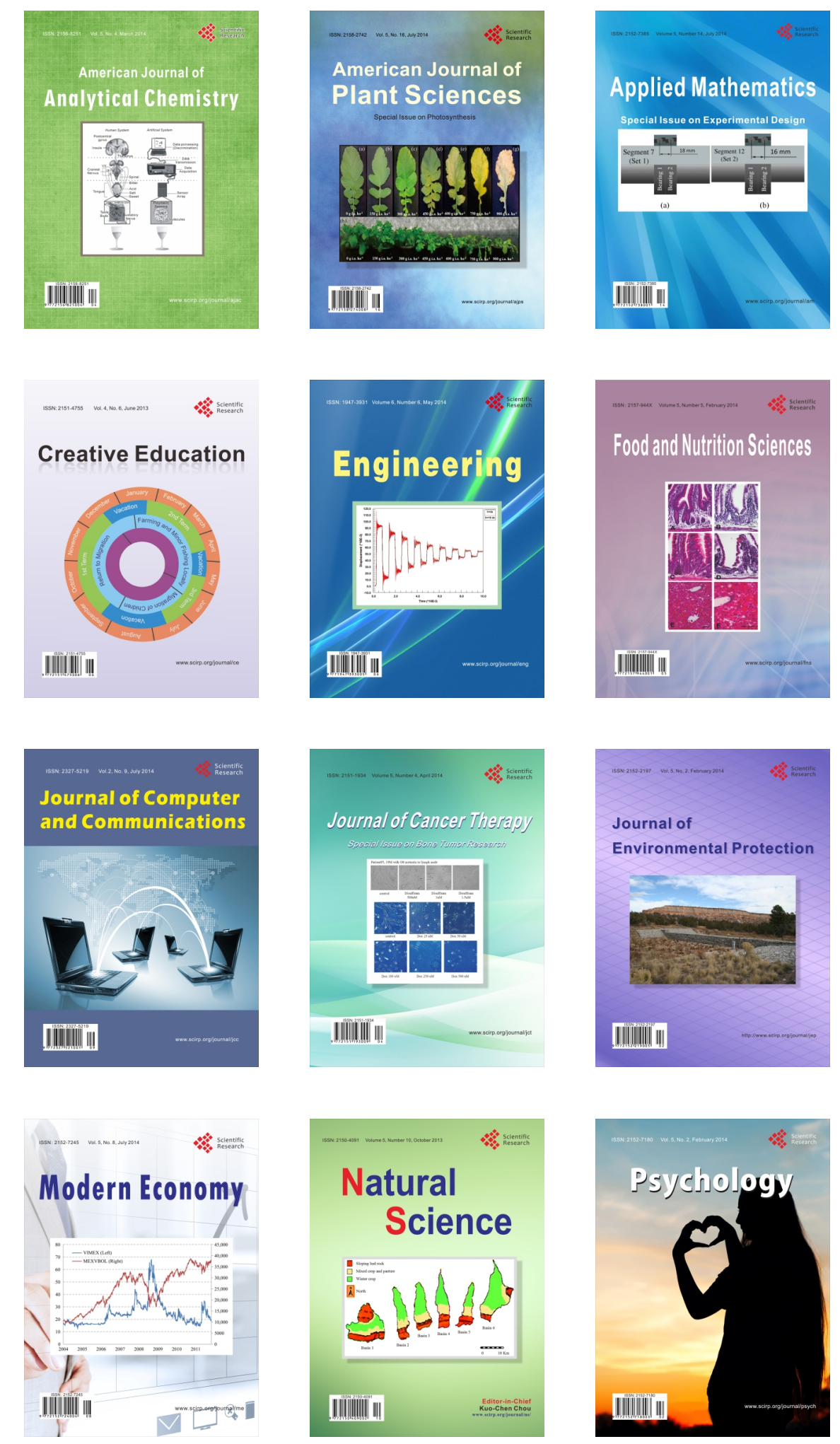